\title{
Networking as a Strategy for Improvement of Science and Mathematics Teaching and Learning in Kenyan Secondary Schools
}

\author{
Godfrey Shedd Mse
}

\begin{abstract}
Quality teaching and learning in an environment that is mostly deprived of teaching and learning resources and scarcity of qualified teachers is a challenge in many African countries. This calls for creativity in the use of available resources so as to benefit a larger population of the teachers and students that may need the available resources.
\end{abstract}

Many schools in Kenya do not have all the human and material resources that they require to effectively meet their needs. Some resources may exist in one school and lack in another. This calls for unselfish use of the resources so that they may benefit other teachers and students who may be in need of the same resources.

Networking is one of the strategies that may be adopted to enable wider use of available resources.

Key words: Networking, teaching and learning resources, human, material.

DOI: $10.7176 / \mathrm{JEP} / 10-21-16$

Publication date:July $31^{\text {st }} 2019$

\section{Introduction:}

It has been suggested in various fora that the teaching of science and mathematics in Kenya leaves a lot to be desired. It is alleged that presentations are made in dull and unimaginative styles that eventually lead to boredom and loss of interest among the learners. This leads to poor performance by pupils in the two subjects.

It is necessary to identify the exact challenges that hinder good performance in science and mathematics and systematically put into motion mechanisms that can address such challenges. The focus should be in making the teaching and learning of science and mathematics interesting and worthwhile. Some of the pertinent issues that manifest themselves in the teaching and learning of mathematics and science, and indeed in all other subjects in the school curriculum, are content, resource materials, pedagogy, motivation of both learners and teachers and conflict management in the schools.

There have been complaints about content outlays for various subjects. The main concerns are that there is too much work to be done in too little time. Syllabi mostly state the topics to be covered, not even offering depth nor order of coverage. In addition there is need to integrate content from various subjects in order to show relationships in areas of knowledge. This calls for a wider exposure by the teacher for him/her to be able to integrate the content.

Resource materials shortages have usually been given as a reason for bad performance in science and mathematics. Availability, relevance and adequacy of books have been highlighted as points of concern. There is no denying that more relevant books that are readily available should be in the market. Other resource materials include access to adequately equipped libraries, journals and other scientific publications, videos.

The teachers" methodology and approach to classroom instruction is another issue that may hinder or promote effective learning of science and mathematics. It is expected that the teacher adopts strategies that endeavour to make learning of these subjects as interesting as possible. Good strategies should be those that oscillate between expository and heuristic methods of instruction. Involvement of pupils in planning and execution of class activities would be a requirement for a well informed teacher.

Motivation of staff and students in each school is a key variable in the determination of performance in every school discipline. Each school should decide the type of incentives to both the students and teachers. The school should carefully use prizes and honours to instill in these parties the worth of tenaciously sticking to and pursuing science and mathematics subjects in our Kenyan Secondary schools 
Actors in teaching and learning are subject to control by the school authorities. There is a definite need to cultivate a good working relationship between the teachers, students, parents and guardians and the management of the school. Such a relationship should be one of mutual trust and based on the recognition of the worth of each other. Studies show that well managed schools almost invariably are also well performing schools.

In its most simplistic view learning may be looked upon as a process of constructing series of interaction networks with the aim of positively changing the behavior of learners. In the process, one who did not know becomes aware through a given deliberate network activity. Networking then can then be viewed as a method for delivery of wants that can lead to educational progress specifically in mathematics and science teaching and learning.

Knowledge, by its own nature needs to be shared. Any innovation in a discipline ought to be disseminated. Various networks need to be formed for such dissemination, and also for highlighting challenges encountered during the process of dissemination and the strategies that could be tried to overcome such challenges. A network that aims at sharing experiences, ideas, materials and resources should go a long way in educating individual schools (and teachers) about what can work and what should be shunned. The end result should be a marked improvement in presentation of programs, generating of activities and evaluating outcomes.

Various levels of networks may be implemented with a view of improving the teaching and learning of mathematics and science

\section{a) Within the School:}

i. Intra Subject Networking:

Those practices which have been found to be beneficial in teaching and learning the subject are shared at the subject level. This should, ideally, take the form of a more experienced, knowledgeable or able teacher sharing experiences with those who may need the same. Aspects of content, appropriate resources, choice and improvisation, methodologies and time to be spent on topical coverage are discussed and and/or demonstrated.

ii. Inter-Subject Networks: There will be aspects of one subject which can be best illustrate the form and approach another subject should take. An illustration of how mathematics may influence the the teaching and learning of Physics and Chemistry may serve as an example. How aspects of Chemistry manifest themselves in Biology is yet another such case. In fact careful analysis should show that science and mathematics are interrelated and concepts in one area may support teaching and learning in the other. So leveraging on the students performance in one subject, the lecturer may reinforce learning in the other subject by using concepts drawn from another subject.

iii. Intra-Departmental Networks: Consultations should be made amongst various subjects in the same department e.g. between Physics and Chemistry, Biology in the Science departments; History, Geography, Economics in the Art Department etc.

Those aspects that can be borrowed can be used to enhance the teaching of the concerned subjects!

iv Inter-departmental Networks: In this type of network, the major consideration is how various departments can aid the other departments to perform better stressful curriculum areas. For example all subjects are taught in English language. Therefore there is a relationship between grasp of English language and ability to understand concepts in the concerned subjects. The languages department can be asked to help the science and mathematics departments.

\section{b) Inter-School Networks:}

(i) Centers of Excellence: In this case, a given school is developed to become a model in particular areas of strength then the school acts as a place from where other schools which are in close proximity can come to learn best practices in the school's area of strength. There can even be exchange of staff, students, and facilities to enhance learning around this model school. After a while the other schools may develop into other centers of excellence. The critical idea is that the model school should not look down upon the other less endowed schools but consider them as partners in the journey to academic excellence. 


\section{Twining with other school:}

A given school may develop a special relationship with another school based on a given criteria. This could be due to the presence of say computers in a given school, better sporting facilities, prowess in particular curriculum areas etc. The twin school could borrow or visit to use those facililties/equipment should need arise. Such twining need not be limited by distance between the twining schools. The further the schools may be, the richer the learning experiences may be owing to greater geographical variation.

\section{(c) School-Industry Links}

Schools should establish concrete links with the industry. The students can benefit in the short term by going to study various aspects of that industry. Examples would include: hospital, power generating plants, cement manufacturing concerns, acid manufacturing plants etc. Some may develop a long term interest and hence work in in these industries after leaving school.

\section{Challenges of Networking Attempts:}

Building bridges between people or institutions will most probably flounder unless the following points are taken into consideration:-

i. The heads of the secondary schools should be involved in the networking exercise inspite of the danger of the heads hijacking the efforts. The heads remain the ultimate point of control in all matters in the school. There can be no decisions being made about the teaching programmes which they do not have knowledge of which can succeed. The very least that can be done is to seek their concurrence with the networking efforts, if not inviting them to be the drivers of the exercise. Any networking activities will require to use resources (both human and physical), facilities as well as time. All these are actually what the school heads control.

ii. The relevant arms of the Ministry of Education should be involved right from the beginning. The ministry can help provide guidance regarding the policy governing some practices that the network might wish to put into place. They may also put in place some liberal and innovative policies that may support the school ventures.

iii. The discussion agenda should be in consultation with the teachers/learners. These should be done at various workshops. There is real need to plan with, rather than for, the teachers. This way, only "felt needs" shall be addressed rather than imaginary ones. This avoids loss of time, resources and effort. Toward this end one needs to conduct purposeful surveys to identify the nature and urgency of such needs at the grassroots levels. Such a data bank of needs can then serve as a reservoir of practical themes of future workshops.

Networking as a strategy for promotion of effective teaching and learning provides opportunities for schools to maximize on the use of scarce resources as well tapping on the talents of teachers to benefit larger school populations. In addition, the strategy provides opportunities for learners to appreciate the interrelationship of the subjects in the curriculum hence enabling students to acquire a holistic perception of the school curriculum.

\section{Reference}

1. Lin, N.(1999) Building a Network Theory of Social Capital in Connections, 22(1): 28-51

2. Reynolds, D.(2003) School Improvement: An Analysis of Implications of Recent School Effectiveness and School Improvement Practice in International Handbook of Educational Change, Edited by Hargreaves, D. , Fullan, M., and Lieberman, A. 241-251, New York, NY: Springer.

3. Nooteboom, B.(2004) Inter-firm collaboration, Networks and Strategy: An Integrated Approach, $1^{\text {st }}$ Edition, New York, NY: Routledge

4. Earl, L and Katz, S(2007) Leadership in Networked Learning Communities: Defining the Terrain, School Leadership and Management, 27:239-258, Taylor and Francis Online

5. Diani, M(2003) Networks and Social Movements: A Research Programme in Social Movements and Networks: Relational Approaches to Collective Action, Edited by Diani M. and McAdam, D. 299-319, Oxford, UK: Oxford University Press 
6. Teddlie, C, and Reynolds D.(2000) International Handbook of School Effectiveness Research, Falmer Press, London, UK

7. Chapman, C. and Allen, T(2005) Partnerships for Improvement: The Specialist Schools Achievement Programme, Coventry, UK: University of Warwick 